\title{
PENGKAJIAN INVESTASI UNIT PENANGKAPAN DALAM UPAYA PEMANFAATAN SUMBERDAYA UDANG PENAEID SECARA BERKELANJUTAN DI PERAIRAN CIREBON UTARA, JAWA BARAT
}

\author{
(AN INVESTMENT STUDIES ON CATCHING TECHNOLOGIES FOR \\ SUSTAINABLE PENAEID SHRIMP RESOURCE MANAGEMENT AT THE \\ NORTH CIREBON COASTAL AREA, WEST JAVA)
}

\author{
Dinarwan $^{1}$, Daniel R Monintja ${ }^{1}$, Akhmad Fauzi ${ }^{2}$ dan Ernani Lubis ${ }^{1}$
}

\begin{abstract}
The results of the research before are mentioned that an increasing of shrimp catching unit on the Cirebon coastal area could be done. So investment of shrimp catching unit could be given. But, before the investment of shrimp catching unit are realized, the feasibility and capacity of those investment have to be evaluated in order to make the condition for sustainability of shrimp resource management. The research objectives are: (i), to analyze the optimal condition of shrimp resource management on the dynamic optimization regime, (ii) to analyze an increasing investment of shrimp catching unit on these region, and (iii) to analyze the financial feasibility of shrimp catching unit activity it self. This research using time series data of fisheries (1983 - 2006) while primary data are collected from interview activities among 90 fishers of shrimp catching unit. The outcomes of the research indicate that with using bio-economics modeling approach : (i) the actual exploitation of penaeid shrimp i.e. Harvest $=4851278 \mathrm{~kg}$ and Effort $=1137$ unit are still lower than the dynamic optimization regime which are Harvest $=7995$ 410,45 $\mathrm{kg}$ and Effort $=4$ 642,51 unit, (ii) an increasing investment on shrimp catching unit are able to be done up to $\mathrm{R} p 40097024$ 651,07 ( \pm 40 billion rupiabs) equivalent to motorize of shrimp catching unit toward 3506 units, and (iii) a financial analysis activities of shrimp catching unit are still feasible with criteria of net present value (NPV) is Rp 36093761,19 and net benefit cost ratio(Net B/C) is 6.5. An increasing of shrimp catching unit are able to be strictly done if the services of fishing port infrastructure on hand well.
\end{abstract}

Keyword : bioeconomic model, dynamic optimization, NPV, penaeid shrimp.

\begin{abstract}
ABSTRAK
Hasil penelitian sebelumnya perihal optimalisasi pengelolaan perikanan tangkap jaring udang di perairan sekitar Cirebon utara Jawa Barat menunjukkan bahwa kuantitas unit penangkapan jaring udang di wilayah perairan Kabupaten Cirebon masih dapat dikembangkan, sehingga iklim investasi pada unit penangkapan jaring udang di wilayah tersebut dapat memberikan harapan yang baik. Namun sebelum investasi terhadap pengembangan kuantitas unit penangkapan jaring udang direalisasikan, perlu kiranya dikaji secara mendalam terhadap kelayakannya dan kapasitasnya tanpa mengganggu aspek kelestarian sumberdaya udangnya. Penelitian bertujuan : (i) menganalisis kondisi optimal tingkat pemanfaatan sumberdaya udang penaeid dengan didasarkan pada pengelolaan sumberdaya perikanan dibawah rezim optimasi dinamik, (ii) menganalisis peluang pengembangan investasi pada unit penangkapan jaring udang, dan (iii) menganalisis kelayakan finansial investasi tersebut. Penelitian ini menggunakan data runtut waktu (time series) perikanan pada periode 1983 - 2006. Sementara data primer diperoleh melalui wawancara terhadap 90 nelayan Jaring Udang. Hasil penelitian dengan menggunakan pendekatan model bioekonomi menunjukkan bahwa : (i) tingkat pemanfaatan sumberdaya udang penaeid pada kondisi aktual dengan tingkat harvest sebesar $4851278 \mathrm{~kg}$ dan effort sebesar 1137 unit armada penangkapan jaring udang ternyata masih lebih kecil daripada kondisi optimal pengelolaan sumberdaya perikanan rezim optimasi dinamik yang memiliki tingkat harvest sebesar 7995 410,45 kg dengan effort 4 642,51 unit armada penangkapannya, (ii) peluang pengembangan investasi pada unit penangkapan jaring udang masih dapat dilakukan hingga senilai Rp 40097024 651,07 ( \pm 40 milyar rupiah) setara dengan motorisasi 3506 unit armada penangkapan jaring udang, dan (iii) hasil analisis finansial dari kegiatan usaha penangkapan jaring udang masih layak diusahakan dengan kriteria nilai NPV sebesar Rp 36093 761,19 dan net $\mathrm{B} / \mathrm{C}$ sebesar 6,5. Upaya pengembangan investasi terhadap armada unit penangkapan jaring udang mensyaratkan agar pelayanan jasa pelabuhan perikanannya ada dalam kondisi yang baik.
\end{abstract}

Kata kunci : model bioekonomi, optimasi dinamik, NPV, udang penaeid.

\footnotetext{
${ }^{1}$ Staf Pengajar Departemen Pemanfaatan Sumberdaya Perikanan (Dept. PSP, FPIK - IPB)

${ }^{2}$ Staf Pengajar Departemen Ekonomi Sumberdaya Lingkungan (Dept. ESL, FEM - IPB)
} 


\section{PENDAHULUAN}

Cirebon merupakan bagian wilayah dari Provinsi Jawa Barat yang dikenal sebagai Kota Udang, karena secara kuantitas produksi udang hasil tangkapan nelayan dari wilayah ini lebih tinggi dibandingkan dengan wilayah lainnya. Kondisi pemanfaatan sumberdaya udang di wilayah perairan Kabupaten Cirebon diduga telah melampaui kondisi lestarinya, namun tetap kegiatan operasi penangkapan udang pada unit alat tangkap jaring udang masih berlangsung hingga sampai saat ini. Besarnya tingkat pemanfaatan sumberdaya udang di wilayah Kabupaten Cirebon tersebut dapat diperlihatkan (data hingga tahun 2005) sebagai berikut : jumlah armada penangkapan udang sudah mencapai 1507 unit untuk alat tangkap dogol, 1016 unit untuk alat tangkap trammel net dan 982 unit untuk alat tangkap jaring klitik; sementara produksi hasil tangkapannya sudah mencapai 6 430,61 ton dari alat tangkap dogol, 4 336,923 ton dari alat tangkap trammel net dan 4187,374 ton dari alat tangkap jaring klitik. Bila diperhatikan kondisi tersebut, kontribusi pemanfaatan sumberdaya udang dari wilayah Cirebon sudah mencapai 92,64 \% dari potensi sumberdaya udang wilayah Laut Jawa (Komnasperikanan, 1998).

Penelitian perihal optimalisasi pengelolaan perikanan tangkap jaring udang di perairan sekitar Cirebon Utara Jawa Barat yang didasarkan pada pendekatan model bioekonomi diperoleh bahwa kondisi pemanfaatan sumberdaya udang di wilayah Kabupaten Cirebon ternyata masih dapat dikembangkan kuantitas effort-nya, namun secara kualitas (lamanya waktu penangkapan) tidak dapat dilakukan karena kegiatan usaha unit penangkapan jaring udang merupakan kegiatan operasi penangkapan yang bersifat one day fishing. Oleh karenanya pengembangan yang dapat dilakukan adalah upaya penambahan terhadap unit armada penangkapan jaring udang, sehingga hal tersebut akan melibatkan kegiatan investasi baru. Mengingat penambahan investasi pada armada unit alat tangkap jaring udang akan berdampak pada keberlanjutan upaya pemanfaatan sumberdaya udang di wilayah tersebut, maka diperlukan adanya kajian terhadap :

(1) Bagaimanakah kondisi optimal dari pengelolaan sumberdaya udang di wilayah perairan Kabupaten Cirebon yang seharusnya dilakukan bila ditinjau dari pengelolaan sumberdaya perikanan spesifik pada rezim optimasi dinamik yang didasarkan melalui pendekatan model bioekonomi ?. Hal ini perlu dikaji karena rezim ini telah mempertimbangkan kedinamisan parameter ekonomi yang terkait aspek investasi, yakni berubah - rubahnya tingkat suku bunga bank.

(2) Seberapa besar investasi yang dapat direalisasikan pada upaya pengembangan kuantitas unit armada penangkapan jaring udang tersebut ? Hal ini sangat perlu dikaji dengan hatihati jangan sampai investasi yang diberikan melebihi kapasitas maksimumnya, sehingga justru membuat sumberdaya udang dapat terkuras melebihi kondisi lestarinya.

(3) Apakah investasi pada unit penangkapan jaring udang tersebut masih layak diberikan pada nelayan ? $\mathrm{Hal}$ inipun perlu dikaji mengingat pemberian investasi tentunya bertujuan agar dapat memberikan manfaat pada nelayan, terutama manfaat finansial.

\section{TUJUAN}

Tujuan penelitian ini adalah :

(1) Menentukan kondisi optimal tingkat pemanfaatan sumberdaya udang di wilayah perairan Kabupaten Cirebon dilihat dari pengelolaan sumberdaya perikanan spesifik rezim optimasi dinamik,

(2) Menentukan peluang pengembangan investasi pada motorisasi unit armada penangkapan jaring udang dibawah kondisi pengelolaan sumberdaya perikanan rezim optimasi dinamik, dan

(3) Menentukan kelayakan finansial investasi pada kegiatan usaha penangkapan jaring udang di wilayah perairan Kabupaten Cirebon.

\section{METODE PENELITIAN}

\subsection{Metode}

Penelitian ini dilakukan dengan menggunakan metode studi kasus, yakni berusaha mengangkat kasus investasi unit penangkapan dalam upaya pengelolaan sumberdaya perikanan udang penaeid secara berkelanjutan di wilayah perairan Kabupaten Cirebon, Provinsi Jawa Barat. 


\subsubsection{Daerah dan waktu penelitian}

Penelitian dilakukan di wilayah pesisir Kabupaten Cirebon (Kecamatan : Kapetakan, Cirebon Utara, Mundu, Astanajapura, Babakan dan Losari) dimana terdapat populasi armada penangkapan jaring udang yang terbesar di wilayah Provinsi Jawa Barat. Penelitian lapangan berlangsung selama \pm 12 bulan yang dimulai pada bulan Maret 2006 sampai dengan Maret 2007.

\subsubsection{Sumber dan macam data}

Data yang diperlukan pada penelitian ini bersumber dari data lapangan (data primer) maupun data hasil studi pustaka (data sekunder). Data primer diperoleh melalui wawancara langsung dengan responden nelayan jaring udang, sedangkan data sekunder diperoleh melalui berbagai instansi terkait, yaitu : dinas perikanan, koperasi mina, tempat pelelangan ikan, pusat pendaratan ikan, toko - toko tempat berjualan berbagai keperluan operasi penangkapan udang, dan lembaga keuangan formal/informal.

\subsubsection{Teknik pengambilan contoh}

Contoh responden diambil dengan menggunakan teknik stratified random sampling. Teknik ini dipilih karena karakteristik populasi pemilikan perahu motor tempel menggambarkan adanya kelas - kelas atau stratifikasi tertentu pada besaran kekuatan motor tempelnya. Dari masing - masing sub populasi berdasarkan penggunaan jenis alat tangkap jaring udang yang beragam tersebut, diambil contoh sebanyak 30 responden sehingga total contoh yang dianalisis sebanyak 90 responden.

\subsubsection{Analisa data}

Analisis hasil tangkap per upaya penangkapan :

Analisis hasil tangkap per upaya penangkapan (catch per unit effort) dilakukan dengan menggunakan formula CPUE (Clark, 1985) sebagai berikut :

$C P U E_{t}=\mathrm{Y}_{\mathrm{t}} / \mathrm{E}_{\mathrm{t}}$

dimana :

$Y_{t}=$ hasil tangkap udang $(\mathrm{kg})$ pada waktu $\mathrm{t}$

$E_{t}=$ jumlah (unit) armada jaring udang pada waktu t.

Perkembangan hasil tangkap dan upaya penangkapan selama periode 1983 s/d 2006 (selama 24 tahun) dianalisis melalui trend analysis dengan pendekatan trend linear yang didasarkan pada metoda kuadrat terkecil (least square methode).

\subsection{Analisis Present Value :}

Metode present value merupakan suatu metode penghitungan seluruh rente ekonomi yang akan datang (future value of rent atau FVR) dari pemanfaatan sumberdaya perikanan berdasarkan nilai pada masa sekarang (present value of rent atau $P V R$ ). Rente sumberdaya perikanan (dalam hal ini adalah udang) dapat ditulis (Clark, 1985) sebagai berikut :

$$
\begin{aligned}
\pi & =p H_{t}-c_{t} E_{t} \ldots \ldots \ldots \ldots . . \\
\pi & =\left(a-b H_{t}\right) H_{t}-c_{t} E_{t}
\end{aligned}
$$

dimana :

$$
\pi=\text { rente sumberdaya perikanan udang }
$$

$p=$ harga jual udang

$a=$ intercept kurva permintaan

$b=$ slope (kemiringan)

$H_{t}=$ hasil tangkap lestari

$E_{t}=$ upaya (effort)

$c_{t}=$ biaya per unit upaya

$t=$ periode waktu

Bila diasumsikan biaya per unit upaya adalah konstan, maka PVR dari sumberdaya perikanan udang dapat ditulis sebagai berikut :

$$
V_{t}=\frac{\left(\Pi_{t}\right)}{-----}
$$

dimana $\delta$ adalah social discount rate untuk $\mathrm{t}$

Dalam situasi tertentu nilai $\delta$ dapat didekati sebagai nilai suku bunga simpanan dan pinjaman di perbankan.

\subsection{Analisis Biaya}

Komponen biaya yang diperhitungkan adalah :

1) Komponen biaya variabel rata-rata yang meliputi biaya-biaya : solar, oli, es, ransum dan perawatan.

2) Komponen biaya tetap rata-rata yang meliputi biaya-biaya : pembuatan tenda (tempat peneduh) di kapal/perahu, ijin usaha dan penyusutan.

\subsection{Analisis Pendugaan Parameter Model Bioekonomi}

Standarisasi upaya dapat menggambarkan upaya secara satu kesatuan unit, yakni unit jaring udang. Standarisasi upaya dan produksi aktual, kemudian dianalisis guna memperoleh fungsi hasil tangkap lestari dan nilai optimal dari parameter : stock udang, hasil tangkap, upaya (effort) dan rente ekonominya pada 
kondisi maximum sustainable yield (MSY), open access (OA), maximum economic yield (MEY) dan optimasi dinamik.

Pendugaan parameter model bioekonomi dilakukan terhadap parameter biologi, yaitu: konstanta daya dukung perairan $(K)$, konstanta pertumbuhan alami (r) dan konstanta daya tangkap (q). Untuk menduga parameter $K, r$ dan $q$ digunakan metoda Algoritma Fox (Fauzi, 2005) sebagai berikut :

$$
\begin{aligned}
q & =\text { geomean }|\ln (x / y) / z| \\
x & =\left(z / C P U E_{t}\right)+1 / b \\
y & =\left(z / C P U E_{t+1}\right)+1 / b \\
z & =-(a / b)-\left\{\left(C P U E_{t}+C P U E_{t+1}\right) / 2\right\} \ldots(5) \\
K & =a / q \ldots \ldots \ldots \ldots \ldots \ldots \ldots \ldots \ldots \ldots \ldots \ldots \ldots \ldots \ldots \ldots \ldots \ldots \ldots \ldots \ldots \ldots \ldots \ldots \ldots \ldots \ldots \ldots \ldots \ldots \ldots \ldots \ldots \ldots \ldots \ldots \ldots \ldots \ldots \ldots \ldots \ldots \ldots \ldots
\end{aligned}
$$

Koefisien a dan b diperoleh melalui pendugaan dengan melakukan regresi sederhana antara CPUE dan Effort.

Parameter biaya penangkapan per upaya penangkapan ( $\mathrm{c}$ ) dihitung dari ratarata biaya penangkapan total responden nelayan jaring udang di wilayah penelitian, sedangkan variabel harga udang (p) ditentukan berdasarkan rata-rata harga per bulan selama periode Maret 2006 sampai dengan Maret 2007. Data biaya penangkapan haruslah diubah terlebih dahulu kedalam nilai riil, kemudian disesuaikan dengan indeks harga konsumen (consumer price index) tahunan dari BPS untuk mendapatkan nilai biaya series tahunan. Konversi ke nilai riil (baik terhadap harga maupun biaya) dimaksudkan agar dapat menghilangkan pengaruh inflasi.

Tahap selanjutnya adalah proses penghitungan kondisi optimal pemanfaatan sumberdaya udang, yakni terhadap parameter : (i) stok sumberdaya udang, (ii) produksi hasil tangkapan, (iii) upaya penangkapan (effort) dan (iv) rente ekonominya pada kondisi MSY (maximum sustainable yield), kondisi $O A$ (open access), kondisi sole owner (MEY) dan kondisi optimasi dinamik $(O D)$. Pada kondisi MSY (maximum sustainable yield) pemanfaatan sumberdaya udang lebih diperhatikan terhadap keamanan aspek biologinya, sedangkan pada kondisi OA (open access) pemanfaatan sumberdaya udang lebih diperhatikan pada kekhawatirannya terhadap status pemanfaatan sumberdaya udang yang mana semua pihak dibolehkan memanfaatkannya.

Langkah selanjutnya adalah proses penghitungan kondisi optimal pemanfaatan sumberdaya udang pada kondisi statis rezim MEY (maximum economic yield) dan kondisi dinamis rezim Optimasi Dinamik. Penghitungan kondisi optimal $M E Y$ dan optimasi dinamik kemudian dibandingkan dengan kondisi MSY dan OA. Hasil perbandingan tersebut dapat digunakan oleh pengambil kebijakan pengelolaan sumberdaya udang (dalam hal ini Dinas Perikanan dan Kelautan setempat) dalam penetapan kondisi mana yang diinginkannya.

Penghitungan terhadap nilai optimal pengelolaan sumberdaya udang dapat didekati dengan menggunakan metode surplus produksi (Graham, 1935).

Fungsi upaya hasil tangkap (yield effort curve) atau fungsi produksi lestari yang digunakan adalah sebagai berikut :

$$
\begin{aligned}
H & =K q E-\left(q^{2} K / r\right) E^{2} \\
H / E & =K q-\left(q^{2} K / r\right) E \\
U & =a-\beta E \quad \ldots \ldots \ldots . . .
\end{aligned}
$$

dimana :

$$
\begin{aligned}
U & =H / E=C P U E \\
a & =K q \\
\beta & =K q^{2} / r
\end{aligned}
$$

Variabel U dan E dapat diperoleh melalui teknik regresi data time series, sehingga nilai koefisien $a$ dan $\beta$ dapat diketahui. Koefisien a dan $\beta$ identik dengan a dan $\mathrm{b}$ pada perolehan proses algoritma fox. Bila $a=K q$ dan $\beta=K q^{2} / r$ masing-masing disubstitusi pada fungsi produksi lestari (8), maka diperoleh fungsi produksi lestari dalam bentuk kuadrat, yaitu :

$$
H=a E-\beta E^{2}
$$

Nilai MSY dapat diperoleh dengan menurunkan fungsi yield effort tersebut terhadap effort yang dibuat sama dengan nol (nilai maksimum). Formula yang digunakan dalam penetapan nilai lestari dari pengelolaan sumberdaya udang yaitu sebagai berikut :

$$
\begin{aligned}
& \mathrm{E}_{\mathrm{MSY}}=\mathrm{a} / 2 \beta=\mathrm{Kqr} / 2 \mathrm{Kq}^{2}=\mathrm{r} / 2 \mathrm{q} \\
& \mathrm{H}_{\mathrm{MSY}}=\mathrm{a}(\mathrm{a} / 2 \beta)-\beta\left(\mathrm{a}^{2} / 4 \beta^{2}\right)=\mathrm{Kr} / 4 . \\
& \mathrm{X}_{\mathrm{MSY}}=\mathrm{K} / 2 . \ldots \ldots \ldots \ldots \ldots \ldots \ldots \ldots \ldots \ldots \ldots \ldots \ldots \ldots \ldots \ldots \ldots \ldots \ldots \ldots \ldots \ldots \ldots \ldots \ldots \ldots
\end{aligned}
$$

Bila kondisi lestari telah diketahui, maka kondisi $O A$ dan $M E Y$ dapat ditentukan pula. Formula yang digunakan dalam penetapan nilai $O A$ dan $M E Y$ dari pengelolaan sumberdaya udang adalah sebagai berikut :

$$
\begin{aligned}
& \boldsymbol{E}_{O A}=r / q(1-c / K p q) \ldots \\
& \boldsymbol{X}_{\mathbf{O A}}=c / p q \ldots \ldots \ldots \ldots \ldots \ldots \\
& \boldsymbol{H}_{\mathbf{O A}}=r c / p q(1-c / K p q) \\
& \boldsymbol{E}_{M E Y}=r / 2 q(1-c / K p q \\
& \boldsymbol{X}_{M E Y}=K / 2(1+c / K p q)
\end{aligned}
$$


$\boldsymbol{H}_{\text {MEY }}=r K / 4(1+c / K p q)(1-c / K p q)(23)$ Kondisi optimal dinamik menggambarkan situasi bahwa stok ikan dapat dianggap sebagai capital yang memiliki dua manfaat, yakni dapat dipanen saat kini atau dapat dipanen pada masa yang akan datang (berperan sebagai investasi). Manfaat kini dan yang akan datang melibatkan adanya penggunaan discount rate. Conrad (1999) mengemukakan adanya the fundamental equation of renewable resources sebagai berikut :

$\partial F / \partial x+(\partial \pi / \partial x) /(\partial \pi / \partial h)=\delta$

$\operatorname{dan} \mathrm{F}(\mathrm{x})=\mathrm{h}$

Telah diketahui bahwa :

$\partial F / \partial x=r(1-2 x / K)$

$\partial \pi / \partial x=c h / q x^{2}$

$\partial \pi / \partial h=(p-c / q x)$

Dengan mensubstitusi ketiga persamaan di atas, maka diperoleh :

$r(1-2 x / K)+\left(c h / q x^{2}\right) /(p-c / q x)=\delta$

$c h=\delta-r(1-2 x / K) q x^{2}(p-c / q x)$

$h=x / c(p q x-c)\{\delta-r(1-2 x / K)\} .$. (29)

$h=\Phi(X)$ merupakan sebuah kurva yang bergantung pada semua parameter bioekonomi, yaitu : $K, q, r, p, c$ dan $\delta$.

Dengan mensubstitusi fungsi pertumbuhan $F(x)=r x(1-x / K)$ kedalam persamaan (29) diatas, maka diperoleh kondisi optimal dari stok ikan, tingkat panen dan besarnya tingkat effort, yaitu :

$r x(1-x / K)=x / c(p q x-c)\{\delta-r(1-2 x / K)\}$

$\boldsymbol{X O D}_{\boldsymbol{D}}=K / 4\{(c / K p q+1-\delta / r)+\sqrt{ }\{(c / K p q$

$\left.+1-\delta / r)^{2}+(8 c \delta / K p q r)\right\}$

$\boldsymbol{h}_{O D}=r x_{O D}\left(1-x_{O D} / K\right)$

$\boldsymbol{E}_{O D}=h_{O D} / q x_{O D}$

\subsection{Analisis Investasi Unit Penangkapan Jaring Udang}

Investasi pada kegiatan perikanan tangkap adalah modal atau capital yang dibutuhkan pada awal periode pelaksanaan kegiatan penangkapan ikan. Investasi yang dibutuhkan umumnya digunakan untuk pembelian kapal, mesin - mesin dan alat tangkap. Oleh karenanya terminologi yang dimaksudkan pada investasi unit alat tangkap jaring udang adalah modal investasi. Untuk menjalankan investasi yang sudah ditanamkan diperlukan adanya modal kerja atau dikenal sebagai biaya operasional penangkapan ikan. Komponen biaya operasional terdiri dari komponen biaya tetap dan biaya variabel.

Modal investasi dikeluarkan satu kali pada awal periode dan dimanfaatkan selama beberapa periode sesuai dengan umur ekonomisnya, sementara modal kerja dikeluarkan setiap periode pemanfaatan daripada modal investasi. Apabila modal investasi diasumsikan completely reversible maka biaya modal investasi menjadi komponen biaya variabel. Oleh karenanya keseluruhan komponen biaya (yang didalamnya sudah terkandung modal investasi) pada setiap periodenya dapat dinyatakan sebagai berikut :

$C_{\text {total }} E_{t}=\left\{c+(\delta+\gamma) c_{K}\right\} E_{t}$

dimana :

$$
\begin{array}{ll}
C_{\text {total }} & =\text { biaya total } \\
c & =\text { biaya variabel } \\
Y & =\text { depresiasi investasi } \\
\delta & =\text { discount rate } \\
E_{t} & =\text { effort pada periode } \mathrm{t}
\end{array}
$$

Dalam kasus kegiatan perikanan unit penangkapan jaring udang di wilayah pesisir Cirebon, investasi diasumsikan memiliki sifat irreversible. Hal ini dimungkinkan karena jarang terjadi transaksi jual - beli kapal ikan berikut perangkat penangkapannya.

\section{HASIL PENELITIAN}

\subsection{Perkembangan Produksi (Hasil Tangkapan), Upaya Penangkapan Jaring Udang dan CPUE}

Hasil penelitian optimalisasi pengelolaan perikanan tangkap jaring udang di perairan sekitar Cirebon utara Jawa Barat menunjukkan bahwa kondisi perkembangan produksi udang hasil tangkapan nelayan di wilayah Kabupaten Cirebon pada periode 1983 - 2006 menunjukkan kecenderungan yang semakin meningkat dengan persamaan trend : $T=-306282+445158 t$. Sementara kondisi perkembangan upaya penangkapan jaring udang (dilihat dari jumlah satuan unit penangkapan) di wilayah Kabupaten Cirebon pada periode 1983 - 2006 menunjukkan kecenderungan yang semakin meningkat pula dengan persamaan trend : $T=1980+24,7 t$. Di sisi lain perkembangan CPUE periode 1983 - 2006 menunjukkan kondisi yang juga meningkat dengan persamaan :

$$
T=349+133 t .
$$

\subsection{Analisis Model Bioekonomi}

Berdasarkan pendekatan analisis bioekonomi didalam pengelolaan sumberdaya perikanan ternyata diperoleh kondisi - kondisi sebagai berikut :

(i) Fungsi produksi lestari $\boldsymbol{H}_{\mathbf{M S Y}}=2725 \mathrm{E}$ - 0,216 $E^{2}$. Berdasarkan fungsi tersebut dapat digambarkan bahwa 
pemanfaatan sumberdaya udang di wilayah Kabupaten Cirebon kondisi lestarinya sudah dilampaui pada periode $1998-2006$.

(ii) Kondisi optimal pada rezim lestari dapat diperlihatkan bahwa cadangan stok sumberdaya udang yang dapat dipertahankan sebesar $9493 \quad 714,99$ $\mathrm{kg}$, produksi hasil tangkapan yang dapat dipanen (harvest) sebanyak 8 594 473,38 kg dengan pemanfaatan banyaknya upaya penangkapan (effort) sebesar 6308 unit penangkapan jaring udang. Berdasarkan optimasi pemanfaatan sumberdaya udang pada kondisi yang demikian, maka tingkat rente ekonomi yang diperoleh adalah sebesar Rp 44307763 946,34 (Tabel 1).

(iii) Pada rezim open access dapat diperlihatkan bahwa cadangan stok sumberdaya udang yang dapat dipertahankan sebesar $5435 \quad 738,99$ $\mathrm{kg}$, produksi hasil tangkapan yang dapat dipanen (harvest) sebanyak 7 024 234,09 $\mathrm{kg}$ dengan pemanfaatan banyaknya upaya penangkapan (effort) sebesar 9004 unit penangkapan jaring udang. Berdasarkan optimasi pemanfaatan sumberdaya udang pada kondisi yang demikian, maka tingkat rente ekonomi yang dapat diperoleh adalah sebesar Rp 0,00 (Tabel 1).

(iv) Pada rezim sole owner (MEY) dapat diperlihatkan bahwa cadangan stok sumberdaya udang yang dapat dipertahankan sebesar 12211 584,48 $\mathrm{kg}$, hasil tangkapan yang dapat dipanen (harvest) sebanyak $7 \quad 890$ $098,12 \mathrm{~kg}$ dengan pemanfaatan banyaknya upaya penangkapan (effort) sebesar 4502 unit penangkapan jaring udang. Berdasarkan optimasi pemanfaatan sumberdaya udang pada kondisi yang demikian, maka tingkat rente ekonomi yang diperoleh sebesar Rp 52803311 366,58 (Tabel 1).

(v) Pada rezim optimasi dinamis (OD) dapat diperlihatkan bahwa cadangan stok sumberdaya udang yang dapat dipertahankan sebesar 12000 186,52 $\mathrm{kg}$, hasil tangkapan yang dapat dipanen (harvest) sebanyak $7 \quad 995$ $410,45 \mathrm{~kg}$ dengan pemanfaatan banyaknya upaya penangkapan (effort) sebesar 4642 unit penangkapan jaring udang. Berdasarkan optimasi pemanfaatan sumberdaya udang pada kondisi yang demikian, maka tingkat rente ekonomi yang dapat diperoleh sebesar Rp 53096161 302,91 (Tabel $1)$.

Tabel 1 Hasil analisis optimasi pemanfaatan sumberdaya udang di wilayah perairan Kabupaten Cirebon, Tahun 2006

\begin{tabular}{crrrr}
\hline Parameter & $\begin{array}{c}\text { Kondisi Lestari } \\
(\text { MSY })\end{array}$ & \multicolumn{1}{c}{$\begin{array}{c}\text { Open } \\
\text { Access }\end{array}$} & \multicolumn{1}{c}{$\begin{array}{c}\text { Sole Owner } \\
(M E Y)\end{array}$} & \multicolumn{1}{c}{$\begin{array}{c}\text { Optimasi } \\
\text { Dinamis }\end{array}$} \\
\hline$X(\mathrm{~kg})$ & 9493714,99 & 5435 & 12211584,48 & 12000186,52 \\
& & 738,99 & & \\
$H(\mathrm{~kg})$ & 8594473,38 & 7024 & 7890098,12 & 7995410,45 \\
& & 234,09 & & \\
$E($ unit $)$ & 6307,87 & 9004,09 & 4502,05 & 4642,51 \\
$\pi($ Rp) & 44307763 & 0,00 & 52803311 & 53096161 \\
& 946,34 & & 366,58 & 302,91 \\
\hline
\end{tabular}

(vi) Terkait dengan kepentingan investasi, hasil analisis melalui pendekatan model bioekonomi tersebut di atas perlu diperluas dengan penambahan rezim optimasi dinamik didalam analisisnya. Rezim optimasi dinamik merupakan rezim pengelolaan sumberdaya perikanan yang mempertimbangkan disamping parameter ekonomi yaitu biaya operasi penangkapan ikan dan harga komoditi hasil tangkapan, juga memasukkan parameter tingkat potongan (discount rate) sumberdaya ikan. Parameter discount rate merupakan parameter ekonomi yang bersifat dinamis karena sangat dipengaruhi oleh tingkat interest rate. Dilibatkannya rezim optimasi dinamik didalam pengelolaan sumberdaya udang di wilayah perairan Kabupaten Cirebon, maka prioritas pengembangan kuantitas armada 
penangkapan jaring udang dapat dilakukan pada rezim ini dengan pertimbangan rezim optimasi dinamik lebih bersifat dinamis.

(vii) Gambaran kondisi optimal dari keempat rezim pengelolaan sumberdaya perikanan tersebut di atas dapat dijadikan acuan penilaian terhadap kondisi tingkat pemanfaatan sumberdaya udang di wilayah perairan Kabupaten Cirebon. Kondisi aktual pemanfaatan sumberdaya udang di wilayah perairan Kabupaten Cirebon berada pada posisi sebagai berikut : a). hasil tangkapan yang dapat dipanen (harvest) sebanyak $4851278,00 \mathrm{~kg}$ dan b). effort yang digunakan dalam upaya menghasilkan tingkat harvest tersebut adalah sebanyak 1137 unit jaring udang.

Berdasarkan gambaran kondisi optimal keempat rezim pengelolaan sumberdaya perikanan dan kondisi aktual pemanfaatan sumberdaya udang di wilayah perairan Kabupaten Cirebon, maka dapat dilihat bahwa kondisi tingkat pemanfaatan aktual sumberdaya udang di wilayah perairan Kabupaten Cirebon masih berada di bawah kondisi optimal keempat rezim pengelolaan yang ada. Bila difokuskan pada banyaknya effort $(E)$ yang ada saat ini, maka kondisi tersebut masih memungkinkan untuk pengembangannya secara kuantitas. Besarnya potensi pengembangan kuantitas unit jaring udang pada masing-masing rezim pengelolaan sumberdaya ikan dapat dilihat pada tabel 2. Perlu diperhatikan bahwa upaya pengembangan terhadap kuantitas armada penangkapan jaring udang haruslah mengacu pada salah satu rezim pengelolaan sumberdaya perikanan yang paling realistis dan memperhatikan aspek keberlanjutannya (sustainability). Berdasarkan pertimbangan tersebut, maka upaya pengembangan terhadap kuantitas armada penangkapan jaring udang dapat mengacu pada rezim optimasi dinamik. Rezim optimasi dinamik adalah rezim pengelolaan sumberdaya perikanan yang bukan hanya mempertimbangkan aspek biologi semata, namun juga mempertimbangkan aspek dinamika ekonomi secara keseluruhan.

Tabel 2 Kondisi aktual dan potensi pengembangan armada unit penangkapan jaring udang di wilayah perairan Kabupaten Cirebon, Provinsi Jawa Barat

\begin{tabular}{|c|c|c|c|}
\hline $\begin{array}{c}\text { Kondisi } \\
\text { Rezim Pengelolaan }\end{array}$ & $\begin{array}{l}\text { Kondisi } \\
\text { Aktual }\end{array}$ & $\begin{array}{c}\text { Tingkat } \\
\text { Pemanfaatan }\end{array}$ & $\begin{array}{c}\text { Potensi } \\
\text { Penambahan }\end{array}$ \\
\hline $\begin{array}{l}\text { Sustainable (Lestari) : } \\
-\mathrm{H}=8594473,38 \mathrm{~kg} \\
-\mathrm{E}=6308 \text { unit }\end{array}$ & $\begin{array}{c}4851278,00 \mathrm{~kg} \\
1137 \text { unit }\end{array}$ & $\begin{array}{l}56,45 \% \\
18,02 \%\end{array}$ & $\begin{array}{l}43,55 \% \\
81,92 \%\end{array}$ \\
\hline $\begin{array}{l}\text { Open Acces : } \\
-\mathrm{H}=7024234,09 \mathrm{~kg} \\
-\mathrm{E}=9004 \text { unit }\end{array}$ & & $\begin{array}{l}69,06 \% \\
12,63 \%\end{array}$ & $\begin{array}{c}30,94 \\
87,37 \%\end{array}$ \\
\hline $\begin{array}{l}\text { Sole Owner } \\
-\mathrm{H}=7890 \text { 098,12 kg } \\
-\mathrm{E}=4502 \text { unit }\end{array}$ & & $\begin{array}{l}61,49 \% \\
25,26 \%\end{array}$ & $\begin{array}{l}38,51 \% \\
74,74 \%\end{array}$ \\
\hline $\begin{array}{l}\text { Optimasi Dinamis: } \\
-\mathrm{H}=7995410,45 \mathrm{~kg} \\
-\mathrm{E}=4643 \text { unit }\end{array}$ & & $\begin{array}{l}60,68 \% \\
24,49 \%\end{array}$ & $\begin{array}{l}39,32 \% \\
75,51 \%\end{array}$ \\
\hline
\end{tabular}

Fenomena masih rendahnya kondisi effort (E) unit armada penangkapan jaring udang di wilayah perairan Kabupaten
Cirebon dibandingkan dengan keempat rezim pengelolaan sumberdaya perikanan dapat diperhatikan pada gambar 1 . 
TR, TC

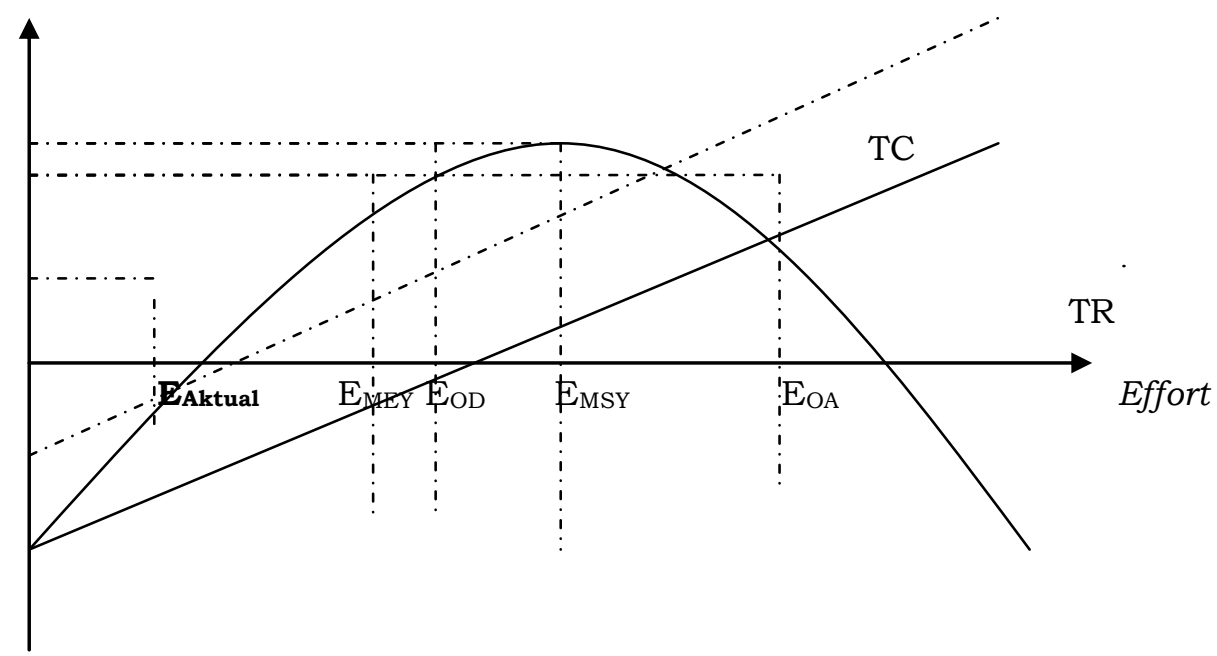

Gambar 1 Posisi effort (E) aktual terhadap keempat rezim pengelolaan sumberdaya udang di wilayah Kabupaten Cirebon

(vii) Hasil analisis optimalisasi investasi dari pemanfaatan sumberdaya udang di wilayah Kabupaten Cirebon dapat diperhatikan bahwa pengembangan investasi terkait dengan upaya motorisasi armada penangkapan jaring udang dapat diprioritaskan dilakukan dibawah koordinasi pengawasan rezim optimasi dinamik (OD) senilai $\mathrm{Rp} 40$ 097024651,07 ( \pm 40 milyar rupiah) setara dengan penambahan motorisasi armada penangkapan jaring udang sebanyak 3506 unit.

(viii) Pada program pengembangan investasi yang akan dilakukan, pertimbangan penting lainnya yang perlu diperhatikan adalah kelayakan dari investasi yang akan ditanamkan tersebut. Berdasarkan hasil analisis kelayakan investasi (financial cost benefit analysis) diperoleh bahwa kegiatan investasi motorisasi unit penangkapan jaring udang memang layak untuk dilakukan, yakni dengan nilai - nilai kriteria investasinya sebagai berikut : $N P V$ sebesar $\mathrm{Rp} 36$ 093761,19 dan net $B / C$ sebesar 6,5. (ix) Pada rezim optimasi dinamik besaran discount rate dapat disimulasikan dengan besaran variasi antara $0 \%$ sampai dengan $50 \%$ per tahun dengan jarak antara $5 \%$ agar dapat dilihat pengaruhnya terhadap parameter cadangan stok $(X)$, tingkat panen $(H)$ dan kuantitas banyaknya effort $(E)$ (Clark, 1976). Hasil simulasi tersebut memperlihatkan bahwa semakin tinggi nilai discount rate, maka tingkat pemanfaatan sumberdaya akan semakin meningkat sehingga cadangan sumberdaya akan semakin menurun (Tabel 3). Pada kondisi yang demikian dapat diperhatikan pula bahwa upaya penangkapan akan semakin meningkat. Untuk menghindari terjadinya pemanfaatan berlebih, maka parameter discount rate melalui besaran parameter tingkat interest rate dapat dijadikan salah satu variabel kendala yang dapat dipertimbangkan oleh pengelola sumberdaya udang di wilayah tersebut. 
Tabel 3 Hasil simulasi keseimbangan optimal pada rezim optimasi dinamik pengelolaan sumberdaya udang di wilayah Kabupaten Cirebon, Tahun 2006

\begin{tabular}{cccc}
\hline $\begin{array}{c}\text { Discount } \\
\text { Rate }\end{array}$ & $\begin{array}{c}\text { Cadangan Sumberdaya }(X) \\
(\mathrm{kg})\end{array}$ & $\begin{array}{c}\text { Tingkat Panen }(H) \\
(\mathrm{kg})\end{array}$ & $\begin{array}{c}\text { Effort } \\
(\mathrm{unit})\end{array}$ \\
\hline & & & \\
0,00 & 12211584,48 & 7890098,12 & 4502 \\
0,05 & 12067504,12 & 7962799,65 & 4598 \\
0,10 & 11926221,76 & 8030244,89 & 4692 \\
0,15 & 11787751,50 & 8092653,86 & 4784 \\
0,20 & 11652103,60 & 8150245,13 & 4874 \\
0,25 & 11519284,41 & 8203235,26 & 4962 \\
0,30 & 11389296,36 & 8251838,35 & 5048 \\
0,35 & 11262137,90 & 8296265,47 & 5133 \\
0,40 & 11137803,56 & 8336724,18 & 5215 \\
0,45 & 11016283,94 & 8373418,13 & 5296 \\
0,50 & 10897565,79 & 8406546,54 & 5375 \\
\hline
\end{tabular}

Sumber : Data diolah

\section{PEMBAHASAN}

\subsection{Perkembangan Produksi (Hasil Tangkapan), Upaya Penangkapan Jaring Udang dan CPUE}

Hasil analisis terhadap aspek-aspek produksi (hasil tangkapan), upaya penangkapan jaring udang dan CPUE diperoleh persamaan trend linear yang kesemuanya memiliki slope positip. Hal tersebut menandakan secara teoritis bahwa akan terjadi adanya peningkatan kuantitas terhadap produksi (hasil tangkapan), upaya penangkapan jaring udang dan CPUE nya. Terjadinya perkembangan kuantitas upaya penangkapan yang menyebabkan adanya peningkatan produksi ternyata didukung pula dengan adanya perkembangan produktivitas alat tangkap (Tabel 4). Hal tersebut diharapkan akan membuka kesempatan berusaha yang menguntungkan bagi nelayan sehingga prasarana dan sarana yang dibutuhkan nelayan dapat diantisipasi pula oleh pemerintah.

Tabel 4. Trend perkembangan produksi (hasil tangkapan), upaya penangkapan jaring udang dan CPUE

\begin{tabular}{ccccc}
\hline Tahun & $\begin{array}{c}\text { Produksi } \\
\text { (hasil tangkapan) } \\
(\mathrm{kg})\end{array}$ & $\begin{array}{c}\text { Upaya penangkapan } \\
\text { jaring udang } \\
\text { (unit) }\end{array}$ & $\begin{array}{c}\text { CPUE } \\
(\mathrm{kg} / \mathrm{unit}) \\
\left({ }^{*}\right)\end{array}$ & $\begin{array}{c}\text { CPUE } \\
(\mathrm{kg} / \mathrm{unit}) \\
(* *)\end{array}$ \\
\hline 2007 & 10822668 & 2600 & 4162,56 & 4239,16 \\
2008 & 11267826 & 2625 & 4292,51 & 4400,60 \\
2009 & 11712984 & 2650 & 4420,00 & 4562,03 \\
2010 & 12464420 & 2675 & 4659,60 & 4723,47 \\
2011 & 12603300 & 2700 & 4667,89 & 4884,90 \\
2012 & 13048458 & 2725 & 4788,42 & 5046,34 \\
2013 & 13493616 & 2750 & 4906,77 & 5207,77 \\
2014 & 13938774 & 2775 & 5022,98 & 5369,21 \\
2015 & 14383932 & 2800 & 5137,12 & 5530,64 \\
\hline
\end{tabular}

$(*) C P U E=$ produksi/upaya

(**) Trend CPUE

\subsection{Aplikasi Model Bioekonomi}

Fungsi produksi lestari yang diperoleh dapat menggambarkan kondisi produksi lestarinya. Pada periode 1998-2006 ternyata kondisi produksi aktual telah melampaui kondisi lestarinya. Hal ini menunjukkan bahwa benar sejak tahun 1998 pemanfaatan sumberdaya udang di wilayah perairan Kabupaten Cirebon telah 
harus diwaspadai karena telah melampaui kondisi lestarinya $\left(\mathrm{H}_{\text {lestari }} / \mathrm{H}_{\text {aktual }}<1\right)$. Hasil analisis tersebut berbeda bila digunakan model bioekonomi. Pada hasil analisis model bioekonomi diperoleh gambaran bahwa hasil tangkapan optimal pada kondisi lestarinya adalah sebesar 8594 $473,38 \mathrm{~kg}$. Hasil tangkapan optimal tersebut kenyataannya dilampaui hanya pada periode $2001-2005$.

Hasil analisis model bioekonomi pada rezim pengelolaan open access menunjukkan kondisi tingkat produksi optimalnya adalah sebesar 7024 234,09 $\mathrm{kg}$, pada rezim sole owner tingkat produksi optimalnya adalah sebesar 7890 098,12 $\mathrm{kg}$, dan pada rezim optimasi dinamik tingkat produksi optimalnya adalah sebesar 7995 410,45 kg, Kondisi ketiga rezim tersebut telah dilampaui pada periode 2001 - 2005. Berdasarkan keempat rezim pengelolaan sumberdaya perikanan, yakni rezim : lestari, open access, sole owner dan optimasi dinamik dapat dikatakan bahwa memang pada periode 2001 - 2005 kondisi pemanfaatan sumberdaya udang di wilayah perairan Kabupaten Cirebon telah berlebihan. Hal ini diduga keras karena pada periode tersebut terjadi devaluasi kurs nilai rupiah terhadap dolar Amerika Serikat yang sangat drastis sehingga mendorong exportir udang menguras sumberdaya udangnya agar dapat mengekspor udang sebanyak mungkin.

Hasil analisis model bioekonomi pada rezim pengelolaan lestari, open access, sole owner dan optimasi dinamik menunjukkan bahwa kondisi effort optimal adalah sebesar 6308 unit, 9004 unit, 4502 unit dan 4 642 unit. Sementara kondisi effort aktual masih berada di bawahnya. Hal ini menunjukkan bahwa penambahan jaring udang di wilayah perairan Kabupaten Cirebon masih sangat memungkinkan, asalkan tingkat produksinya tidak melebihi kondisi optimalnya. Terkait dengan aktivitas investasi, maka pengembangan kuantitas jaring udang di wilayah tersebut seyogianya berada dibawah pengawasan rezim optimasi dinamik karena dengan pengawasan rezim tersebut akan diperoleh tingkat pendapatan yang paling besar dan kedinamisan variabel - variabel ekonomi telah diantisipasi.

\subsection{Analisis Investasi}

Bila diperhatikan Tabel 5, maka dapat diperhatikan bahwa pengembangan investasi unit penangkapan jaring udang masih dapat dilakukan. Pada rezim pengelolaan sumberdaya lestari (MSY), pengembangan investasi unit penangkapan jaring udang masih terbuka sebesar $82 \%$ dengan nilai nominal Rp $59 \quad 143 \quad 737$ 137,18 \pm lima puluh sembilan milyar rupiah) setara dengan motorisasi effort sebanyak $5 \quad 171$ unit. Pada rezim pengelolaan sumberdaya sole owner $(M E Y)$, pengembangan investasi unit penangkapan jaring udang masih terbuka sebesar $74,75 \%$ dengan nilai nominal Rp 38490 608596,56 ( \pm tiga puluh delapan setengah milyar rupiah) setara dengan motorisasi effort sebanyak 3365 unit. Sementara pada rezim pengelolaan sumberdaya optimasi dinamik, pengembangan investasi unit penangkapan jaring udang masih terbuka sebesar $75,52 \%$ dengan nilai nominal Rp 40097024651,07 ( \pm empat puluh milyar rupiah) setara dengan motorisasi effort sebanyak 3506 unit. 
Tabel 5 Optimalisasi investasi dan potensi pengembangan investasi unit penangkapan jaring udang pada rezim pengelolaan sumberdaya udang di wilayah Kabupaten Cirebon

\begin{tabular}{|c|c|c|c|}
\hline $\begin{array}{c}\text { Kondisi } \\
\text { Rezim Pengelolaan } \\
\end{array}$ & $\begin{array}{c}\text { Kondisi } \\
\text { Aktual } \\
\end{array}$ & $\begin{array}{c}\text { Tingkat } \\
\text { Pemanfaatan } \\
\end{array}$ & $\begin{array}{c}\text { Potensi } \\
\text { Pengembangan } \\
\end{array}$ \\
\hline $\begin{array}{l}\text { Sustainable (Lestari) : } \\
-\mathrm{H}=8594473,38 \mathrm{~kg} \\
-\mathrm{E}=6308 \text { unit } \\
-\mathrm{I}=\mathrm{Rp} 72 \quad 142 \quad 873 \\
789,02\end{array}$ & $\begin{array}{l}-\mathrm{H}=4851278,00 \mathrm{~kg} \\
-\mathrm{E}=1137 \text { unit } \\
-\mathrm{I}=\mathrm{Rp} 12999136 \\
652,00\end{array}$ & $18 \%$ & $\begin{array}{l}-\mathrm{E}=5 \quad 171 \text { unit } \\
-\mathrm{I}=\mathrm{Rp} 59143737 \\
137,18 \\
82 \%\end{array}$ \\
\hline $\begin{array}{l}\text { Open Acces : } \\
-\mathrm{H}=7024234,09 \mathrm{~kg} \\
-\mathrm{E}=9004 \text { unit } \\
-\mathrm{I}=\mathrm{Rp} 102979490 \\
496,82\end{array}$ & & $\begin{array}{l}\text { Telah } \\
\text { Melampaui } \\
\text { kondisi } \\
\text { lestari }\end{array}$ & $\begin{array}{l}\text { Tidak } \\
\text { ada } \\
\text { rekomendasi }\end{array}$ \\
\hline $\begin{array}{l}\text { Sole Owner: } \\
-\mathrm{H}=7890098,12 \mathrm{~kg} \\
-\mathrm{E}=4502 \text { unit } \\
-\mathrm{I}=\mathrm{Rp} 51489745 \\
248,41\end{array}$ & & $25,25 \%$ & $\begin{array}{c}-\mathrm{E}=3365 \text { unit } \\
-\mathrm{I}=\mathrm{Rp} 38490608 \\
596,56 \\
74,75 \%\end{array}$ \\
\hline $\begin{array}{l}\text { Optimasi Dinamis : } \\
-\mathrm{H}=7995410,45 \mathrm{~kg} \\
-\mathrm{E}=4643 \text { unit } \\
-\mathrm{I}=\mathrm{Rp} 53096161 \\
302,91\end{array}$ & & $24,48 \%$ & $\begin{array}{l}-\mathrm{E}=3506 \text { unit } \\
-\mathrm{I}=\mathrm{Rp} 40097024 \\
651,07 \\
75,52 \%\end{array}$ \\
\hline
\end{tabular}

Sumber : Data diolah

Skala prioritas pengembangan investasi unit penangkapan jaring udang seyogianya didasarkan pada nilai investasi yang paling realistis, yakni pada rezim pengelolaan sumberdaya optimasi dinamik, dimana pada rezim ini telah memperhitungkan kedinamisan perubahan tingkat suku bunga perbankan. Kondisi tersebut didukung pula oleh layaknya hasil kriteria investasi yang diperoleh $(N P V>0$ dan Net $B / C>1$ ) pada kegiatan usaha penangkapan jaring udang di wilayah Kabupaten Cirebon. Diharapkan program pengembangan investasi pada rezim pengelolaan sumberdaya optimasi dinamik ini didukung dengan adanya tambahan stimulus fiskal yang diluncurkan oleh pemerintah pada APBN 2009. Program pengembangan investasi pada rezim pengelolaan sumberdaya optimasi dinamik ini juga mensyaratkan agar prasarana dan sarana pendukung kegiatan usaha perikanan tangkap dapat dipersiapkan terlebih dahulu.

\section{KESIMPULAN DAN REKOMENDASI}

\subsection{Kesimpulan :}

Hasil kajian pengelolaan sumberdaya udang dan investasi terhadap unit penangkapan jaring udang serta upaya untuk menjaga keberlanjutannya di wilayah perairan Kabupaten Cirebon dapat disimpulkan sebagai berikut :

i. Didasarkan pada pendekatan model bioekonomi, tingkat pemanfaatan sumberdaya udang penaeid yang pada kondisi aktual sebesar 1137 unit armada penangkapan jaring udang dengan tingkat produksi sebesar 4851 $278 \mathrm{~kg}$ ternyata masih lebih kecil dari pada kondisi optimal keempat rezim pengelolaan sumberdaya perikanan, yakni rezim : lestari, open access, sole owner (MEY) dan optimasi dinamik (OD). Oleh karenanya pengembangan motorisasi armada penangkapan jaring udang masih memungkinkan untuk dilakukan.

ii. Pengembangan investasi terkait dengan upaya penambahan motorisasi armada penangkapan jaring udang dapat dilakukan dibawah koordinasi 
pengawasan rezim optimasi dinamik (OD) senilai Rp 40097024 651,07 ( 440 milyar rupiah) setara dengan penambahan motorisasi armada penangkapan jaring udang sebanyak 3 506 unit.

iii. Pengembangan investasi terhadap armada penangkapan jaring udang layak dilakukan karena secara finansial telah memenuhi parameter kriteria investasinya.

\subsection{Rekomendasi :}

Pengembangan investasi terhadap motorisasi armada penangkapan jaring udang mensyaratkan tersedianya prasarana dan sarana pendukung kegiatan usaha penangkapan jaring udang (terutama pusat pendaratan ikannya). Adanya tambahan stimulus fiskal yang diluncurkan oleh pemerintah pada APBN 2009 seyogianya dapat dimanfaatkan oleh pihak berwenang (DKP) dalam mengantisipasi rencana pengembangan investasi tersebut.

\section{DAFTAR PUSTAKA}

Clark, C. W. and Gordon R Munro. 1975. The Economics of Fishing and Modern Capital Theory, A Simplified Approach Journal of Environmental Economics and Management 6, p. 287 - 296. Academic Press, Canada.
Clark, C. W. 1976. Mathematical Bioeconomics : The Optimal Management of the Renewable Resources. John Willey and Sons Inc.

Clark, C. W. 1985. Bioeconomic Modelling and Fisheries Management. John Willey and Sons Inc.

Dasgupta, A. K. and Pearch, D. W. 1978. Cost Benefit Analysis Theory and Practice. The Macmillan Press Ltd. London and Basington.

Fauzi, Akhmad. 2004. Ekonomi Sumberdaya Alam dan Lingkungan : Teori dan Aplikasi. Penerbit PT Gramedia Pustaka Utama, Jakarta.

Fauzi, Akhmad dan Anna, Suzy. 2005. Pemodelan Sumberdaya Perikanan dan Kelautan untuk Analisis Kebijakan. Penerbit PT Gramedia Pustaka Utama, Jakarta.

Hirshleifer, J. 1970. Investment, Interest, and Capital. Prentice Hall Inc., London.

Komisi Nasional Pengkajian Sumberdaya Perikanan Laut. 1998. Potensi, Pemanfaatan dan Peluang Pengembangan Sumberdaya Ikan Laut di Perairan Indonesia. Jakarta.

Kadariah. 1986. Evaluasi Proyek, Analisa Ekonomi, Edisi Satu. Lembaga Penerbit Fakultas Ekonomi UI, Jakarta.

Levy, H. and M. Sarnat. 1978. Capital Investment and Financial Decisions. Prentice Hall Inc., London. 